\title{
Supraventricular Extrasystoles, CTCAE
}

National Cancer Institute

\section{Source}

National Cancer Institute. Supraventricular Extrasystoles, CT CAE. NCI Thesaurus. Code C54944.

An adverse event characterized by premature atrial contractions of the heart caused by signals originating from ectopic atrial sites or the atrioventricular node. 